\title{
Corrigendum: Proactive Control Mediates the Relationship Between Working Memory and Math Ability in Early Childhood
}

\author{
Chunjie Wang ${ }^{1}$, Baoming $\mathrm{Li}^{1}$ and Yuan Yao ${ }^{2 *}$ \\ ${ }^{1}$ Institute of Brain Science and Department of Psychology, School of Education, Hangzhou Normal University, Hangzhou, \\ China, ${ }^{2}$ Department of Psychology, Suzhou University of Science and Technology, Suzhou, China
}

Keywords: proactive control, working memory, math ability, individual differences, early childhood

\section{A Corrigendum on}

Proactive Control Mediates the Relationship Between Working Memory and Math Ability in Early Childhood

by Wang, C., Li, B., and Yao, Y. (2021). Front. Psychol. 12:611429. doi: 10.3389/fpsyg.2021.611429

\section{OPEN ACCESS}

Approved by:

Frontiers Editorial Office

Frontiers Media SA, Switzerland

${ }^{*}$ Correspondence:

Yuan Yao

lisayuan@zju.edu.cn

Specialty section:

This article was submitted to

Cognition,

a section of the journal

Frontiers in Psychology

Received: 13 September 2021 Accepted: 14 September 2021 Published: 30 September 2021

Citation:

Wang C, Li B and Yao Y (2021) Corrigendum: Proactive Control Mediates the Relationship Between Working Memory and Math Ability in Early Childhood.

Front. Psychol. 12:775003. doi: 10.3389/fpsyg.2021.775003
In the original article, there was an error in the Funding statement as published. The correct Name for the Funder "Hangzhou Normal University (2020QDL006 and 20JYXK035)" is "the Starting Research Fund from Hangzhou Normal University (No. 2020QDL006), and the cultivation project of the province-leveled preponderant characteristic discipline in the College of Education of Hangzhou Normal University (20JYXK035)". The corrected Funding statement is shown below.

This research was supported by grants to CW from the National Natural Science Foundation of China (32000780), the Natural Science Foundation of Zhejiang Province (Q21C090027), China Postdoctoral Science Foundation (no. 2018M630655), the Starting Research Fund from Hangzhou Normal University (no. 2020QDL006), and the cultivation project of the provinceleveled preponderant characteristic discipline in the College of Education of Hangzhou Normal University (20JYXK035), and grants to YY from the Natural Science Foundation of Jiangsu Province (no. BK20190937) and Natural Science Foundation for Universities of Jiangsu Province (no. 19KJB19005).

The authors apologize for this error and state that this does not change the scientific conclusions of the article in any way. The original article has been updated.

Publisher's Note: All claims expressed in this article are solely those of the authors and do not necessarily represent those of their affiliated organizations, or those of the publisher, the editors and the reviewers. Any product that may be evaluated in this article, or claim that may be made by its manufacturer, is not guaranteed or endorsed by the publisher.

Copyright $\odot 2021$ Wang, Li and Yao. This is an open-access article distributed under the terms of the Creative Commons Attribution License (CC BY). The use, distribution or reproduction in other forums is permitted, provided the original author(s) and the copyright owner(s) are credited and that the original publication in this journal is cited, in accordance with accepted academic practice. No use, distribution or reproduction is permitted which does not comply with these terms. 